\title{
Multi-criteria decision making: AHP method applied for network bridge prioritization
}

\author{
Zaharah Allah Bukhsh ${ }^{1}$, Irina Stipanovic Oslakovic ${ }^{2}$, \\ Giel Klanker ${ }^{3}$,Niels Peter $\mathrm{Hoj}^{4}$, Boulent Imam ${ }^{5}$, Yiannis Xenidis ${ }^{6}$ \\ DOI: https://doi.org/10.5592/CO/BSHM2017.3.2 \\ ${ }^{1,2}$ University of Twente, Faculty of Engineering Technology, Department for Construction Management \\ and Engineering, P.O.Box 217, 7500 AE Enschede, Netherlands \\ ${ }^{3}$ Rijkswaterstaat Ministry of Infrastructure and the Environment, Griffioenlaan 23526 LA Utrecht, \\ Netherlands \\ ${ }^{4}$ HOJ Consulting, Brunnen, Switzerland \\ ${ }^{5}$ Department of Civil and Environmental Engineering, University of Surrey, Guildford, Surrey, GU2 7XH, \\ United Kingdom \\ ${ }^{6}$ Department of Civil Engineering, Aristotle University of Thessaloniki, University Campus, 54124, \\ Thessaloniki, Greece \\ E-mails: ${ }^{1}$ z.allahbukhsh@utwente.nl, ${ }^{2}$ i.stipanovic@utwente.nl; ${ }^{3}$ giel.klanker@rws.nl, ${ }^{4}$ niels.hoj@hoj.ch, \\ 5․imam@surrey.ac.uk, ${ }^{6}$ ioxen@ civil.auth.gr
}

\begin{abstract}
In bridge management systems, multi-objective decision-making has emerged as a decision support technique to integrate various technical information and stakeholder values. Different multicriteria decision making techniques and tools have been developed in the last three decades. This paper presents an overview of different approaches to multi-objective decision making at the object and network level, with the purpose of incorporating different aspects of bridge performance goals, which may vary according to technical, environmental, economic and social factors. The example of application of analytic hierarchy process (AHP), as one of the multi criteria decision making method, to a illustrative case study is presented in the paper.
\end{abstract}

Keywords: multi-criteria decision making, bridge management, performance goals.

\section{$1 \quad$ Introduction}

Bridges are key structures of a transport infrastructure system. From an economic viewpoint it is crucial that bridges provide their designed function as part of the infrastructure network systems in an efficient manner. Bridges present a vital link in any roadway network. It is estimated that the ratio of expenses per route $\mathrm{km}$ of bridges or tunnels is 10 times average expenses per route $\mathrm{km}$ of roads (CEDR, 2010). Also the length of bridges compared to the whole length of road network is only app. $2 \%$ but at the same time they present $30 \%$ value of the whole network (PIARC, 1999). When these statistics are taken into consideration it is easy to understand why, in the past few decades, an increasing number of deteriorating bridges led to the development of a number of Bridge Management Systems (BMS) and life cycle maintenance models like for example Branco\&Brito, Frangopol's and Rijkswaterstaat's model (Kaneuji et al. 2006, Airaksinen 2006, BRIME 2000, Noortwijk J.M. et al. 2004).

Profit-driven transport operations, aging infrastructure and adverse climate changes imposed the need of costeffective and improved maintenance strategies. Infrastructure managers are under a lot of pressure to not only reduce network downtime, but also plan, such maintenance policies that could prolong the overall service lifetime of the infrastructure. According to Van der Velde et al. (2013) budget restraints and increased public demand in terms of service and quality put pressure on government bodies that have to manage transport infrastructure systems while dealing with these dynamics. Looking for ways to cope with this issue the attention from infrastructure operators is increasingly turned to asset management. Applying this approach to infrastructure is seen as a way to deal with the pressures that are present on the management of public transportation infrastructure which were discussed above. Moon et al. (2009) describe the different concepts that are involved with infrastructure asset management. According to them, integrating these concepts should lead to a better infrastructure management. The following concepts are described: 1) Performance based engineering and management leads to the definition of performance objectives and correlated metrics, 2) Structural 
identification, health monitoring and intelligent infrastructure are used to monitor and forecast metrics, and 3) Life cycle costs and decision making are used to identify trade-offs. These concepts and their interplay are depicted in Figure 1. In the work presented here, the focus will be on multi-criteria decision making while assessing trade-offs based on different aspects of bridge performance.

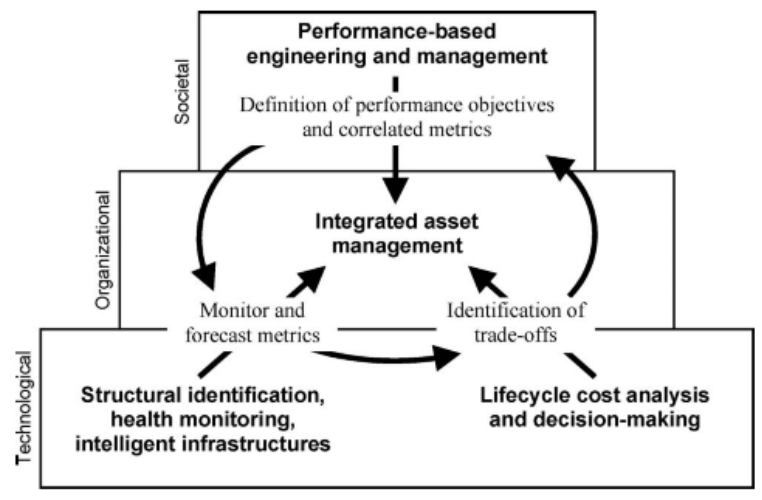

Figure 1: Integration of the different aspects of integrated asset management (Moon et al., 2009)

\section{Identification of trade-offs}

Bridge maintenance planning is a process of deciding the scope, timing, costs, and benefits of future maintenance activities on a specific bridge. Optimization of maintenance activities regarding technical and economic requirements is essential for road owners to fulfil societal expectations. Due to the long life time of the road infrastructure, especially bridge structures (often longer than 50 years), the assessment of technical and economic performance is necessary in order to optimize budget expenditure. Life cycle cost (LCC) analysis and reliability based concepts are well established methodologies for identification and assessment of trade-offs.

\subsection{Object level}

In the current state of the practice, most bridge management systems are very effective at storage and retrieval of all the raw data needed for maintenance planning. With these data it is possible to develop plots of performance over time and to identify possible maintenance alternatives. Based on that, life cycle costs for different maintenance alternatives can be calculated and compared. To express and manage this spectrum of possible futures, the concept of a "candidate" is suggested (Patidar et al. 2007). A "candidate" is hereby defined as a life-cycle activity profile for one bridge, consisting of a sequence of agency activities-including donothing - in each of a sequence of future time periods. Development of alternative candidates and selection of the best one is a cardinal aspect of decision making by the bridge maintenance planner. The planner decides which of the alternative candidates are worthy of consideration and, over time, narrows the list to just one or a small number that the planner then submits to the next level of bridge management (i.e., programming and budgeting at the network level). An example of comparison of different maintenance options and LCC results is shown in Figure 2. However, the focus of existing bridge management systems is still mainly on owner's costs, rarely taking into account other impacts of the bridge, such as environmental impacts, availability, importance on the transport network and society as a whole, etc.

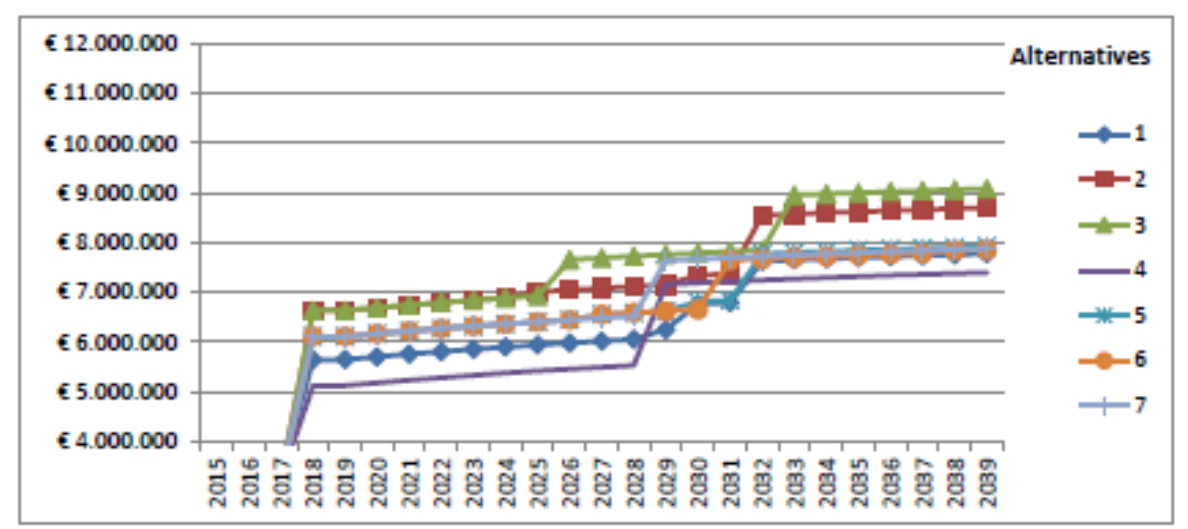

Figure 2: Comparison of different maintenance alternative candidates for life cycle of 25 years (Wolthuis, 2014) 

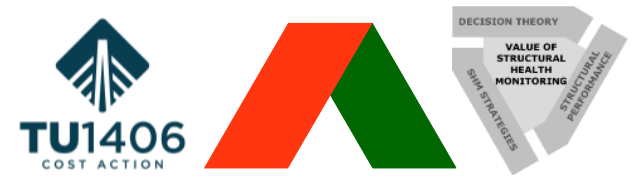

The Value of Structural Health Monitoring for the reliable Bridge Management

Zagreb 2-3 March 2017

\subsection{Network level}

In the course of developing network-level bridge programs, program managers typically face a variety of objectives and constraints. Examples of objectives are to maximize cost effectiveness, to minimize vulnerability to damage, to maximize average condition, and to optimize a utility index that combines various objectives. Constraints include budgetary limits that cannot be exceeded or a minimum level of average bridge performance (Patidar et al., 2017).

The foundation of any decision analysis is a clear statement of goals and belonging performance indicators. To describe the consequences of alternative bridge actions and enable trade-offs between competing goals, it is necessary to identify a set of goals and a set of performance indicators for each goal, as it is shown in Figure 3 .

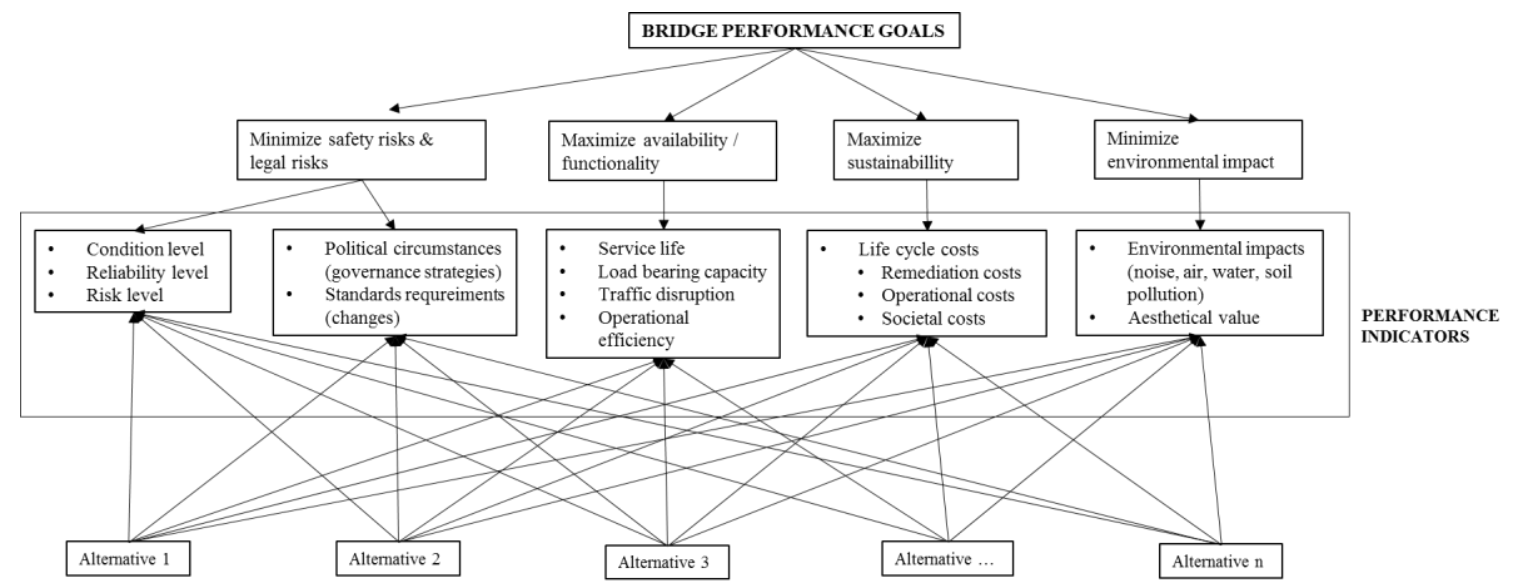

Figure 3: Hierarchy structure for linking multi-objective bridge performance goals and performance indicators (based on Rashidi \& Lemass, 2011)

Based on the work which has been so far done in COST TU 1406 WG 1 (WG 1 Report, 2016) and literature review (Stipanovic et al. 2016; Imam, 2016) for the purposes of this study, a list of general bridge performance goals is proposed, as given in Table 1. A set of performance indicators for each goal clarifies the meaning of each goal and is required to measure the consequences of alternative bridge maintenance actions. Performance indicators are also sometimes referred to as measures, attributes or criteria.

Table 1: Overview of performance goals and performance indicators

\begin{tabular}{lll}
\hline Performance Goal & Performance aspect & Performance indicators* \\
\hline $\begin{array}{l}\text { To provide safe and reliable } \\
\text { network }\end{array}$ & Reliability & $\begin{array}{l}\text { Condition Rating } \\
\text { Reliability Rating } \\
\text { Number of casualties caused by traffic accidents }\end{array}$ \\
& Safety & $\begin{array}{l}\text { Scour Vulnerability Rating } \\
\text { Earthquake Vulnerability Rating } \\
\text { Other Disaster Vulnerability Rating }\end{array}$ \\
\hline To protect from extreme events & Safety & $\begin{array}{l}\text { Availability of the road (\% of time) } \\
\text { Downtime (Traffic delays caused by } \\
\text { maintenance works) }\end{array}$ \\
\hline $\begin{array}{l}\text { To provide responsive and } \\
\text { sustainable network }\end{array}$ & Availability & $\begin{array}{l}\text { Owners costs (LCC, initial costs, maintenance } \\
\text { costs, replacement costs etc.) }\end{array}$ \\
\hline $\begin{array}{l}\text { To minimize agency costs } \\
\text { To minimize its negative }\end{array}$ & Economic aspect & $\begin{array}{l}\text { Importance on the network (Traffic intensity) } \\
\text { impacts on users, local } \\
\text { communities and the } \\
\text { environment }\end{array}$ \\
& environmental aspects & $\begin{array}{l}\text { User delay costs } \\
\text { Societal costs } \\
\text { Environmental impacts }\end{array}$ \\
\hline
\end{tabular}

\footnotetext{
* list not complete, only selected examples provided here
} 


\section{Multi-criteria decision making}

Implicit in any decision-making process is the need to construct, either directly or indirectly, the preference order, so that alternatives can be ranked and the best alternative can be selected. For some decision-making problems, this may easily be accomplished. For example, in case of a decision based on a cost-minimization rule (where the lowest-cost alternative is chosen), the preference order is adequately represented by the natural order of real numbers (representing costs). Hence, in such a case, the preference order need not be constructed explicitly (Patidar et al., 2007).

Multi-criteria decision-making (MCDM) provides a systematic approach to evaluate multiple conflicting criteria in decision making. Conflicting criteria are typical in evaluating options: cost or price is usually one of the main criteria, and some measure of quality (performance level) is typically another criterion, usually in conflict with the cost. MCDM is used to identify and quantify decision-maker and stakeholder considerations about various (mostly) non-monetary factors, in order to compare alternative courses of action (Kabir et al., 2014). Alternatively, the multiple performance criteria can be combined into a so-called utility function, in which all the criteria are brought into a single scale.

In the course of developing network-level bridge programs, program managers typically face a variety of objectives and constraints. Examples of such objectives are given in Table 1, and constraints usually include a budgetary limitation that may not be exceeded or a minimum level of average bridge performance. The overlap between objectives and constraints is a key issue to practical multi-objective optimization of an asset management program.

An important class of decision-making techniques that attempt to construct the preference order by directly eliciting the decision maker's preference is predicated on what is known as utility theory. This, in turn, is based on the premise that the decision maker's preference structure can be represented by a real-valued function called a utility function. Once such a function is constructed, the selection of the appropriate alternative can be done using an optimization method. Broadly speaking, this technique involves three steps (Patidar et al., 2007):

1. Weighting: This assigns relative weights to the multiple criteria.

2. Scaling: Because the performance criteria can be of different units, scaling provides a common scale of measurement and translates the decision maker's preferences for each performance criterion on a $0-100$ scale. This involves developing single-criterion utility functions.

3. Amalgamation: Amalgamation is combining the singlecriterion utility functions using the relative weights into one measure based on mathematical assumptions about the decision maker's preference structure. This involves deriving the functional forms of multi-criteria utility functions.

\subsection{Analytic Hiearchy Process}

The Analytic Hierarchy Process (AHP) is a structured technique for organizing and analyzing complex decisions, based on mathematics and psychology. It was developed by Thomas L. Saaty in the 1970s and has been extensively studied and refined since then. It has particular application in group decision making, and is used around the world in a wide variety of decision situations, in fields such as government, business, industry, healthcare, shipbuilding and education.

Rather than prescribing a "correct" decision, the AHP helps decision makers identify the decision that best suits their goal and their understanding of the problem. It provides a comprehensive and rational framework for structuring a decision problem, for representing and quantifying its elements, for relating those elements to overall goals, and for evaluating alternative solutions.

The analytic hierarchy process aims to arrive at the relative weights for multiple criteria in a realistic manner while allowing for differences in opinion and conflicts that exist in the real world. The analytic hierarchy process can handle quantitative, qualitative, tangible, and intangible criteria. The process is based on three principles: decomposition, comparative judgments, and synthesis of priorities. It constructs a hierarchy and uses pairwise comparisons at each level to estimate the relative weights.

The procedure for using the AHP can be summarized as (Saaty, 2008):

1. Model the problem as a hierarchy containing the decision goal, the alternatives for reaching it, and the criteria for evaluating the alternatives.

2. Establish priorities among the elements of the hierarchy by making a series of judgments based on pairwise comparisons of the elements. For example, when comparing potential purchases of commercial real estate, the investors might say they prefer location over price and price over timing. 

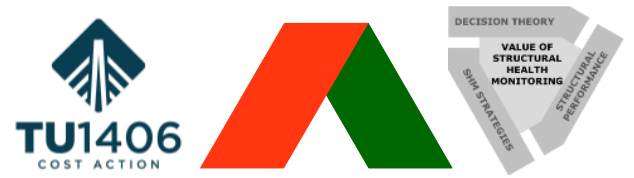

The Value of Structural Health Monitoring for the reliable Bridge Management

Zagreb 2-3 March 2017

3. Synthesize these judgments to yield a set of overall priorities for the hierarchy. This would combine the investors' judgments about location, price and timing for properties A, B, C, and D into overall priorities for each property.

4. Check the consistency of the judgments.

5. Come to a final decision based on the results of this process.

\subsection{Illustrative case study for AHP method}

In this section, an example case is provided to demonstrate the multi-criteria optimization for the bridge maintenance planning. A road network has a number of bridges which might be exposed to deteriorating condition. Due to budget limitations, a decision has to be made regarding the selection of bridge(s) for maintenance. Therefore, the objective of this example is to illustrate the decision making procedure for a bridge(s) selection, where the cost and downtime due to maintenance is aimed to be kept minimum.

For the sake of demonstration, we have considered five bridges depicted as A, B, C, D and E. Each bridge on the network has a number of related attributes such as location, geometry, condition etc. Before assessing the bridge performance on the network level, it is assumed that for each bridge an optimal maintenance alternative has been selected, based on life cycle cost calculations for several alternatives, e.g. three alternatives: do nothing, minor repair, major repair. For the purpose of ranking the bridges in the terms of maintenance prioritization, the following performance indicators have been selected (see Table 1, marked bold): reliability level, maintenance cost, downtime due to the maintenance works, and importance on the network.

Table 2. Representational data for illustrative case

\begin{tabular}{ccccc}
\hline & Reliability & Economy & Availability & Society \\
\hline Bridges & Reliability level & Maintenance cost & Downtime & $\begin{array}{c}\text { Importance on the } \\
\text { network }\end{array}$ \\
Name & Score card & Euros & Hours & $\begin{array}{c}\text { Traffic Intensity } \\
\text { \# cars / day) }\end{array}$ \\
\hline A: B101 & 3 & $500 \mathrm{k}$ & 30 & 9000 \\
\hline B: B109 & 4 & $1000 \mathrm{k}$ & 70 & 10000 \\
\hline C: B207 & 4 & $200 \mathrm{k}$ & 60 & 13000 \\
\hline D: B307 & 5 & $800 \mathrm{k}$ & 180 & 5000 \\
\hline E: B150 & 3 & $500 \mathrm{k}$ & 40 & 5000 \\
\hline
\end{tabular}

The related data for five bridges is provided in Table 2, where indicators are defined as follows: Maintenance cost is a direct (owners) cost which is expected to be incurred during the maintenance procedure. Downtime is defined as the unavailability of the bridge due to planned maintenance activity. The reliability level of a bridge is a constructed value based on the condition indexes. The reliability level only involves those bridges that are critical to perform their intended function. The score card depicting the reliability levels are shown in Table 3.

Table 3 : Reliability level score card

\begin{tabular}{cc}
\hline Reliability Level & Description \\
\hline $\mathbf{1}$ & Very Good (no faults) \\
\hline $\mathbf{2}$ & Good (minor faults well within tolerance) \\
\hline $\mathbf{3}$ & Fair (tolerable faults, no restriction in use necessary) \\
\hline $\mathbf{4}$ & Poor (significant structural defects) \\
\hline $\mathbf{5}$ & Very poor (seriously deficient, mitigation measures necessary) \\
\hline $\mathbf{6}$ & Out of service (on high risk of failure, mitigation needed urgently) \\
\hline
\end{tabular}


Only those assets that are in the optimum range of serviceability, i.e. 1-5 can be considered in the maintenance planning procedure. Bridges having the reliability level of 6 are considered too critical to delay the maintenance actions. Finally, the network importance is defined by the intensity of traffic passing over the bridge each day.

\subsection{Preference structure}

Subjective judgment in the decision making methods plays vital role. The preference structure and procedures for this example is based on analytical hierarchy process proposed by Saaty (1988). To assign the ratio scales to the subjective judgments of comparison, a fundamental scale for pairwise comparison is used. By assigning the ratio scale values, the importance of one attribute (e.g. condition) become clear to another attribute (e.g. cost).

Based on the scale of pairwise comparison ${ }^{1}$, a relative importance of each attribute to define the decision criteria is defined in Table 4. Considering the objective, the decision criteria are to select a bridge for maintenance that has minimum cost, minimum downtime, minimum reliability level, and minimum traffic intensity. Therefore, in comparison of maintenance cost and downtime the intensity of their relative importance is equal to 1 . While, in comparison of maintenance cost and reliability level, the maintenance cost is moderately more important than reliability level with intensity of 3 . It is important to notice that all the comparisons among attributes and their data is made by authors of this paper for demonstration purposes.

Table 4: Subjective judgment to ratio scales

\begin{tabular}{llll}
\hline Criteria & & \multicolumn{2}{c}{ Importance \& Intensity } \\
\hline A & B & Imp & Intensity \\
\hline Maintenance cost & Downtime & A & 1: Equal importance \\
\hline Maintenance cost & Reliability level & A & 3: Moderate \\
\hline Maintenance cost & Traffic Intensity & A & 5: Strong \\
\hline Downtime & Reliability level & A & 3: Moderate \\
\hline Downtime & Traffic Intensity & A & 3: Moderate \\
\hline Reliability level & Traffic Intensity & A & 7: Very Strong \\
\hline
\end{tabular}

The subjective judgment to ratio scales provides a decision criteria matrix. The step of pairwise comparison is repeated four times to compare data values for each bridge to another. For instance, the maintenance cost for each bridge is compared to another and their relative importance is defined. The low maintenance cost will get high intensity value as compared to the higher maintenance cost. These pairwise comparisons of data values yielded four comparison matrixes.

To derive the final weighted scale, the Eigen vector method is used to first reduce the matrix into a value function ranging from 0 to 1 and then to find the largest Eigen value. Irrespective of matrix type either as decision criteria matrix or comparison matrix, the steps to reduce to Eigen vector are similar. The following steps are taken to find the best bridge for maintenance that incur minimal maintenance cost and downtime. To represent the calculation procedure, some steps are adopted from (Ma, Ma, Zhou, \& Ma, 2015):

a) normalize each matrix

$$
\overline{e_{l j}}=\frac{e_{i j}}{\sum_{k=1}^{n} e_{i j}}
$$

Where $e_{i j}$ represents an element in the matrix M. $\bar{e}_{i j}$ represents an element of normalized matrix which is resulted by dividing $e_{i j}$ to sum of its column value. This step results into a normalized matrix.

b) To calculate the geometric mean of each matrix, add all the elements in a row Then divide the sum of values in a row to the number of rows

$$
\overline{w_{l}}=\sum_{j=1}^{n} \overline{e_{\imath \jmath}}
$$

\footnotetext{
${ }^{1}$ Online link to scale: http://bit.ly/2gEluQX
} 

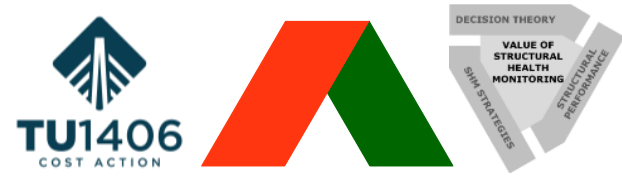

The Value of Structural Health Monitoring for the reliable Bridge Management

This step represents the final weighted score for a matrix, represented as $S_{m}$. The calculation of geometric mean reduces the matrix size to $4 * 1$ and $5 * 1$ for decision matrix and comparison matrix respectively.

$$
S_{m}=\frac{\overline{w_{l}}}{\sum_{j=1}^{n} \overline{w_{J}}}
$$

c) The final step is to calculate the largest value that represents the aggregated preference of reduced maintenance cost and downtime.

$$
M_{j m}=\left(S_{m c}, S_{d}, S_{r l}, S_{t i}\right)
$$

Where $S_{s c}, S_{d}, S_{r l}$ and $S_{t i}$ represent the geometric mean values for maintenance cost, downtime, reliability index and traffic intensity respectively. The final score is obtained by multiplying the judgment matrix represented as $M_{j c}$ to the decision criteria matrix represented as $M_{d c}$.

\subsection{Results}

The result shows the scoring of selected bridge maintenance alternatives for five bridges, when taking into account four different aspects, measured by cost, downtime, reliability level, and traffic intensity at the network level. Prioritization of bridges for maintenance will be done based on the objective to keep the maintenance cost and downtime minimum. The final obtained results are illustrated in Figures 4 and 5.

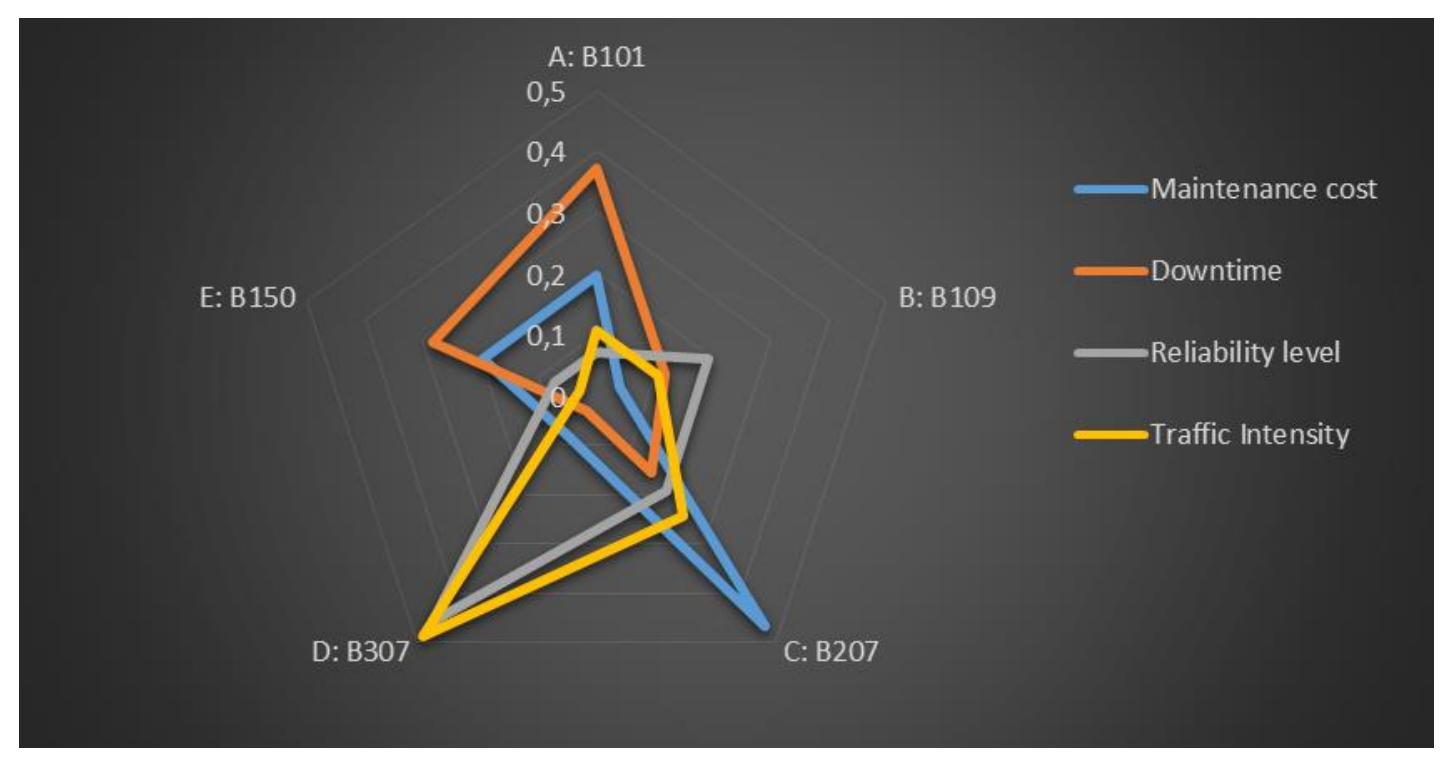

Figure 4: Comparison of performance aspects for five bridges

Before providing the final selection of a single bridge, Figure 4Error! Reference source not found. graphically represents the equation 4 where the final score $\left(S_{m}\right)$ is combined to form a judgment matrix $\left(M_{j m}\right)$. The higher the value of an attribute the more it is preferable with regard to the defined objective. The graph shows that bridge $C: B 207$ is most preferable selection in terms of reduced cost, while bridge A:B101 is best in terms of reduced downtime. Similarly, more conclusions can be drawn e.g. for the maximization of reliability level then bridge $D$ : $B 307$ is scoring the best.

It is important to notice that based on the attribute nature the applied function is defined. For instance, for the maintenance cost and downtime the minimization function is applied whereas for the reliability level and traffic intensity the maximization function is used.

Figure 5 shows the final prioritization result based on the AHP process for bridge maintenance planning, when the objective is set to minimize maintenance costs and minimize downtime. It is shown that bridge $C: 207$ is most preferred in terms reduced cost and downtime whereas B: 109 is least preferred bridge for maintenance. 


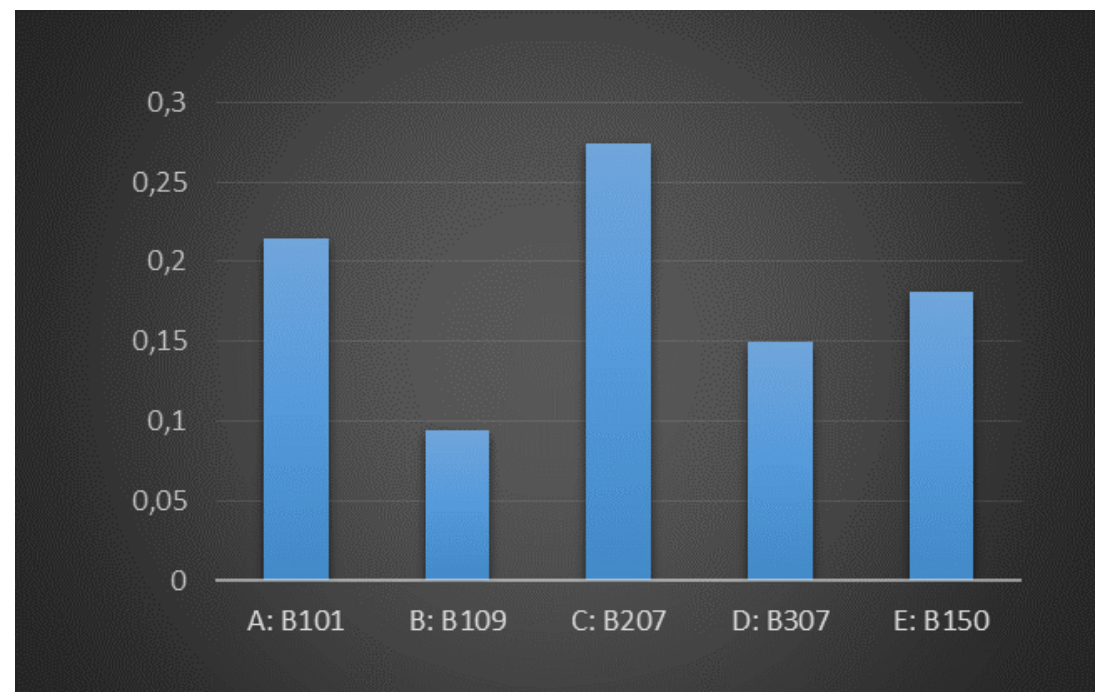

Figure 5: Bridge scoring based multi-criteria decision anaysis

\section{Discussion and Conclusion}

One of the main challenges in future research is how to quantify performance goals other than technical, and how to link network level to the performance requirements on the object level. Network or even societal goals tend to be rather broad in their definition. Furthermore, there is often no exclusive relationship between performance indicators set at a lower level and goals at a higher level. An important notion is that in many countries, the main focus of bridge management is still the condition assessment of the particular objects or elements thereof.

This study provides some guidance on how a program manager can implement multiple performance goals by establishing a multi-criteria decision making framework, based on the performance indicators linked to the performance goals and aspects. In the paper a set of performance goals is proposed, based on the existing practices and literature review, which are linked to the set of performance indicators that include reliability, availability, economy and societal aspects. For the purpose of showing how multi-criteria decision making can be performed, an illustrative case study has been done with the application of AHP method. With this method it was possible to evaluate multiple performance aspects of multiple bridges in order to rank bridge maintenance activities on the network level.

\section{Acknowledgements}

This article is based upon the work from COST Action TU1406, Quality specifications for roadway bridges, standardization at a European level (BridgeSpec), supported by COST (European Cooperation in Science and Technology).

\section{References}

Airaksinen M., Söderqvist M.K. (2006) Bridge life-cycle management in the service of the Finnish Road Administration", Proceedings of the fifth International Workshop on life-cycle cost analysis and design of civil infrastructure systems, 'Life-Cycle cost and performance of civil infrastructure systems', Seoul, Korea, October 16-18, 2006, 71-78.

BRIME: Bridge management in Europe http://www.trl.co.uk/BRIME

CEDR, 2010, Conference of European Directors of Roads, Report on BEXPRAC, March 2010.

COST Action TU 1406 WG1, Technical Report, 2016, Performance Indicators for Roadway Bridgesof COST Action TU1406, ISBN: 978-3-900932-41-1, 2016, http://www.tu1406.eu/wpcontent/uploads/2016/10/COST_TU1406_WG1_TECH_REPORT.pdf

Department for Transportation (DfT), 2013. Strategic road network performance specification 2013-15, London, UK, www.gov.uk/dft 

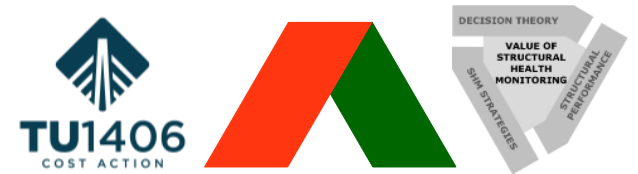

The Value of Structural Health Monitoring for the reliable Bridge Management

Imam B., Lee H.Y., 2016.Environmental performance framework for bridge infrastructure Proceedings of the COST TU 1406 WG 2 Workshop, Delft 20-21 October 2016.

Kabir, G., Sadiq, R., Tesfamariam, S. 2014, A review of multi-criteria decision-making methods for infrastructure management, Structure and Infrastructure Engineering, 2014, Vol. 10, No. 9, 1176-1210.

Kaneuji M., Yamamoto N., Watanabe E., Furuta H. (2006). Bridge management system developed for the local governments in Japan, Proceedings of the fifth International Workshop on life-cycle cost analysis and design of civil infrastructure systems, 'Life-Cycle cost and performance of civil infrastructure systems', Seoul, Korea, October 16-18, 2006, 55-68.

Moon, F. L., Aktan, A. E., Furuta, H., \&Dogaki, M. (2009). Governing issues and alternate resolutionsfor a highway transportation agency's transition to asset management. Structure and InfrastructureEngineering, 5(1), 25-39. http://doi.org/10.1080/15732470701322768

Noortwijk Jan M. van, Frangopol D.M. (2004). Two probabilistic life-cycle maintenance models for deteriorating civil infrastructure", Probabilistic Engineering Mechanics 19, 345-359.

Patidar,V.,Labi,S. , Sinha,K. C, Thompson, P. 2007. Multi-Objective Optimization for Bridge Management Systems, NCHRP REPORT 590, ISBN 978-0-309-42144-7, DOI 10.17226/23147, 2007.

PIARC - World Road Association (1999), Reliability-based Assessment of Highway Bridges, PIARC Paris.

Rashidi, M., Lemass, B. 2011, A Decision Support Methodolo-gy for Remediation Planning of Concrete Bridges, KICEM Journal of Construction Engineering and Project Manage-ment, Vol.1, No.2 / Aug 2011, 110, http://dx.doi.org/10.6106/JCEPM.2011.1.2.001

Saaty, Thomas L. 2008. Decision Making for Leaders: The Analytic Hierarchy Process for Decisions in a Complex World. Pittsburgh, Pennsylvania: RWS Publications. ISBN 0-9620317-8-X.

Stipanovic Oslakovic, I., Hoj, N.P., Klanker, G. 2016. Multi-objective bridge performance goals, IALCCE 2016, Life-Cycle of Engineering Systems: Emphasis on SustainableCivil Infrastructure - Bakker, Frangopol \& van Breugel (Eds)@ 2017 Taylor \& Francis Group, London, ISBN 978-1-138-02847-0r, pp. 540 - 1547.

Velde, J. van der, Klatter, L., Bakker, J. 2010, A holistic ap-proach to asset management in the Netherlands. Proceed-ings of the 5th international conference on Bridge Mainte-nance, Safety and Management, Philadelphia, USA.

Wolthuis, L. 2014. Decision Support System to conduct Life Cycle Cost Analysis for service life road pavement design using an object oriented model, MSc Thesis, University of Twente, http://essay.utwente.nl/66000/. 